\title{
Experimental research on the domestic ORC micro power plant with a commercial biomass boiler
}

\author{
Tomasz Kaczmarczyk ${ }^{1, *}$, Grzegorz Żywica ${ }^{1}$, and Eugeniusz Inhatowicz ${ }^{1}$ \\ ${ }^{1}$ Polish Academy of Sciences, Institute of Fluid Flow Machinery, Department of Turbine Dynamics \\ and Diagnostics, Generała Józefa Fiszera 14, 80-231 Gdańsk, Poland
}

\begin{abstract}
The purpose of the work was to experimentally evaluate the operation of the domestic ORC micro power plant that uses a commercial biomass boiler fueled with wood pellets. The boiler, with a maximum thermal power output of $45 \mathrm{~kW}_{\mathrm{t}}$, uses a heating jacket and thermal oil as a working medium. The prototypical domestic ORC micro power plant was equipped with a multistage radial-flow microturbine that can generate electricity $\left(2.5 \mathrm{~kW}_{\mathrm{e}}\right.$ at a rotational speed of $\left.24,000 \mathrm{rpm}\right)$. The microturbine is a key component of the turbogenerator, which was manufactured in oilfree technology. The turbogenerator's high-speed bearings are lubricated with the low-boiling medium's vapour. The HFE7100 fluid was used as a working medium in the ORC installation. The paper discusses the thermodynamic conditions to be met for effective operation of the boiler and the results of experimental research. The operating characteristics of the ORC installation and the biomass boiler were presented. Problems that occurred while testing the micro-cogeneration power plant with the boiler and their impact on the electric and thermal efficiency of the cycle were discussed.
\end{abstract}

\section{Introduction}

In the European Union countries, the development of modern technologies that can help in reducing global climate changes and $\mathrm{CO}_{2}$ emissions has been observed for the last dozen or so years. The data provided in [1,2] show that in recent years in Poland, hard coal consumption by households and small enterprises accounts for over $30 \%$ of the total domestic consumption. It is estimated that approximately $50 \%$ of the world's energy production is wasted in the form of heat released into the atmosphere, due to the limitations of energy conversion processes [3]. Waste heat can come from various sources, including industrial and domestic installations [4,5]. By using heat recovery systems, it is possible to harvest energy not only from commercial energy systems but also from natural renewable energy resources. Therefore, it is reasonable to consistently introduce new energy technologies and smart energy management systems [6] in order to increase the efficiency and profitability of existing and newly built energy system installations [7]. There are

* Corresponding author: tkaczmarczyk@imp.gda.pl 
promising signs of progress in the field of distributed power generation, which enables high-efficiency generation of electricity, heat or cold. The use of micro-CHP systems can meet the demand for thermal and electric energy in single-family houses in which the demand for electricity does not exceed $10 \mathrm{~kW}_{\mathrm{e}}[8,9]$. Hence the constant search for expansion machines that can be used in CHP systems [10-12]. Commercial solutions with electric power capacities below $10 \mathrm{~kW}_{\mathrm{e}}$ are virtually not available [13], though their potential use in energy-efficient buildings (e.g. public utility buildings or single-family and multi-family houses) appears to be unquestionable. It should be noted, however, that noise is the second largest environmental problem in the European Union, after air pollution [14]. Therefore, new CHP ORC energy installations should be characterised not only by high energy efficiency and operational reliability, low noise and vibration levels but should also have no negative impact on the environment [15].

This article presents the results of research on a small cogeneration system equipped with a biomass boiler. Such installations, with a power output capacity adapted to use them in single-family houses, are not yet available on the market, and their further development will certainly contribute to the implementation of assumptions of the new energy policy of the European Union.

\section{Domestic cogeneration system}

The domestic cogeneration system (Fig. 1) comprises the following components: ORC installation (1), biomass boiler (2) and the heat removal system (fan cooler). A radial-flow microturbine (3), specially designed for this purpose, was used as an expansion machine in the ORC installation. The microturbine (3) is a four-stage device, with the nominal rotational speed of $24,000 \mathrm{rpm}$ at which it can produce $2.5 \mathrm{~kW}_{\mathrm{e}}$ of electric power. It is noteworthy that the micro-turbogenerator (3) is an oil-free machine, equipped with gas bearings lubricated with the low-boiling medium's vapour. The correct operation of the cogeneration system is supervised by the control and conditioning/receiving system for the produced electric energy (4). The system guards against an excessive increase of the microturbine's rotational speed and the electrical operating parameters (current and voltage).

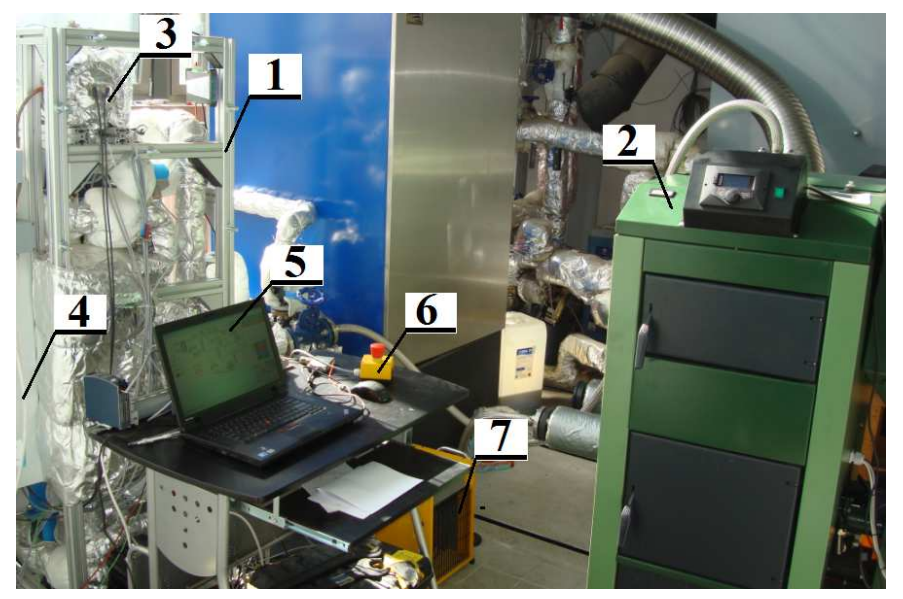

Fig. 1. The photo of the test rig which was taken during tests: 1- ORC installation, 2 - biomass boiler, 3 - radial-flow microturbine, 4 - conditioning/reception/control system for the produced electric energy, 5- control panel, 6 - emergency shutdown button of the ORC system, 7 - electricity receiver (R type) 
In addition, the level of vibration of the microturbine is monitored, and if the permissible vibration level is exceeded, the machine can be stopped using the emergency shutdown button (6). The cogeneration system can work in automatic mode or in manual control mode using the user's desktop (5). As the system uses a three-phase high-speed synchronous (4-pole) electric generator, it was necessary to process the electrical signal. For this purpose, a rectifier system was specially designed with the energy consumption system that uses electric power produced by the microturbine (3). The generated electricity is consumed by a set of DC bulbs with a total electric power of $1 \mathrm{~kW}_{\mathrm{e}}$ and also by an electric heater (7) with a rated power of $5 \mathrm{~kW}_{\mathrm{e}}$. The cycle uses the organic working fluid sold under the trade name HFE7100. This medium is incombustible, inexplosive, nontoxic and environmentally friendly as its ODP (Ozone Depletion Potential) coefficient is zero. The ORC (1) system consists of the following components: microturbine (3), control system (4), evaporator and condenser (that are plate heat exchangers), regenerator (shelland-tube heat exchanger) and circulation pump. The boiler (2) with a thermal power of 45 $\mathrm{kW}_{\mathrm{t}}$, equipped with a heating jacket, was used as a heat source. The thermal oil (Iterm $6 \mathrm{Mb}$ ) whose maximum operating temperature is $280^{\circ} \mathrm{C}$ was employed in the system as a heat carrier. The boiler (2) was equipped with a fuel feeder. During the cogeneration system tests, the biomass-fired boiler used pellets made of softwood (pine and spruce) with was a diameter of $6 \mathrm{~mm}$ and a calorific value of $5 \mathrm{kWh} / \mathrm{kg}$. It should be mentioned that the humidity rate of the biomass was not measured.

\section{Results of the experimental research}

The research of the biomass boiler coupled with the ORC installation was of a longterm nature and lasted continuously for three days. The selected results of the research are presented in the following part of the paper. During measurements, it was found that the maximum temperature of the thermal oil at the boiler outlet and at the evaporator inlet was about $200^{\circ} \mathrm{C}$. Using a thermal imaging camera (FLIR E50), it was estimated that the temperature of the flue gas in the flue was approx. $170^{\circ} \mathrm{C}$ (Fig. 2) and was slightly lower than the temperature of the lid $\left(172^{\circ} \mathrm{C}\right)$ that fixed the screw-conveyor feeder and the fan that supplies boiler with air (Fig. 3).


Fig. 2. The thermal image and photo of the biomass boiler's flue

Fig. 2 shows that the surface temperature of the boiler cover plate was approximately $53^{\circ} \mathrm{C}$. In order to determine the electrical efficiency of the ORC cogeneration system, the tests were carried out in such a way that the electric power produced by the microturbogenerator was constant. An exemplary graph depicting electric power that was produced by the cogeneration system during the tests (over a period of 8,000 seconds) is shown in Fig. 4. 

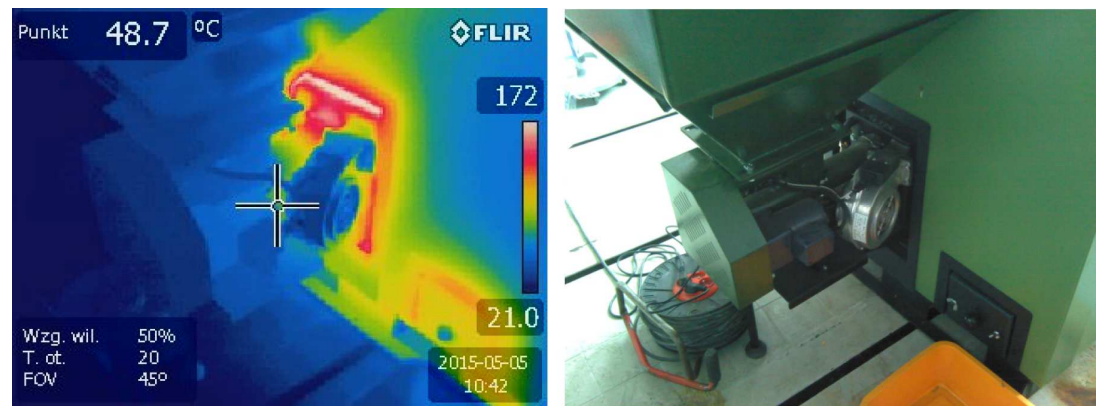

Fig. 3. The thermal image and photo of the system for attaching the feeder and the air fan to the biomass boiler



Fig. 4. Electrical power generated by the cogeneration system vs. time

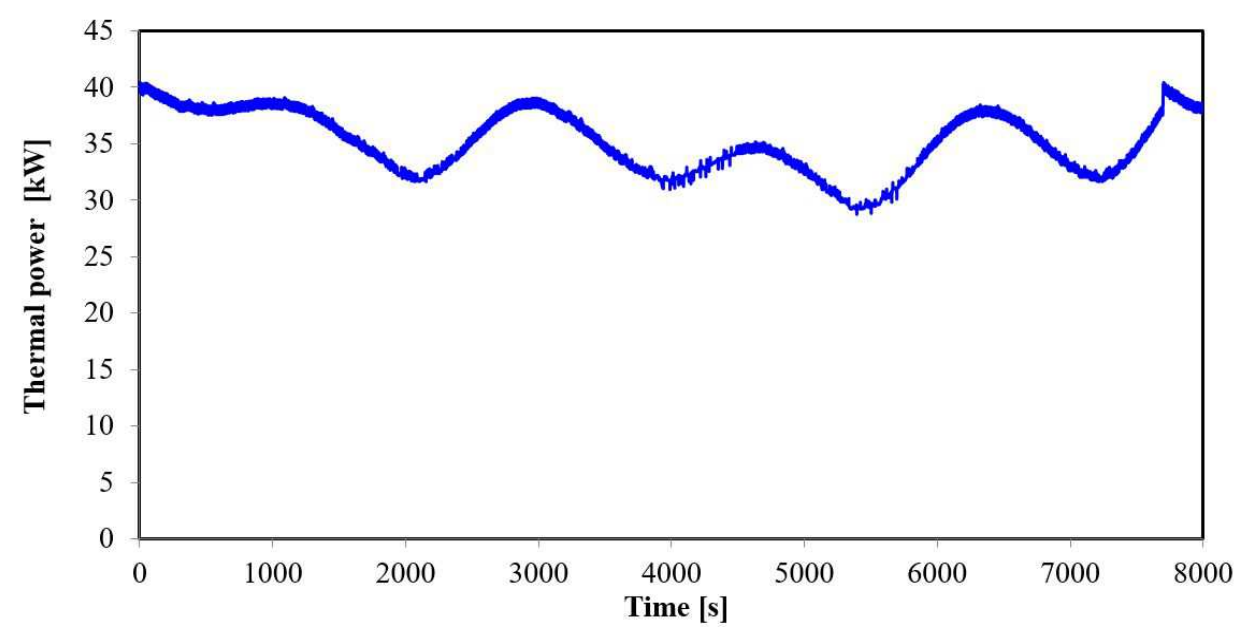

Fig. 5. Thermal power of the biomass boiler vs. time (registered during testing of the ORC cogeneration system) 
The average electric power of the biomass-fired boiler, measured when it operated in the ORC installation, was $1,100 \mathrm{~W}_{\mathrm{e}}$. The thermal power of the biomass boiler was presented in Fig. 5. The thermal power of the boiler varied from $29.5 \mathrm{~kW}_{\mathrm{t}}$ to $40.6 \mathrm{~kW}_{\mathrm{t}}$, and the average value was about $36.7 \mathrm{~kW}_{\mathrm{t}}$.

There are two reasons for the fluctuations in the thermal power level: 1. the high thermal inertia of the boiler as there were about 200 litres of thermal oil in the boiler and in the heating cycle (i.e. in the evaporator and piping together with its fittings); 2 . the feeder and the air fan worked in cycles-resulting from the PID controller settings done by the manufacturer of the boiler; other thermophysical properties of the oil compared to water. Moreover, heating the thermal oil can cause an excessive and uneven increase in the oil temperature inside the boiler's heating jacket, which in turn causes incorrect operation of the temperature controller, which is intended for use in water cycles. The fluctuations in the thermal power of the boiler caused changes in the electrical efficiency of the organic Rankine cycle, which was shown in Fig. 6.

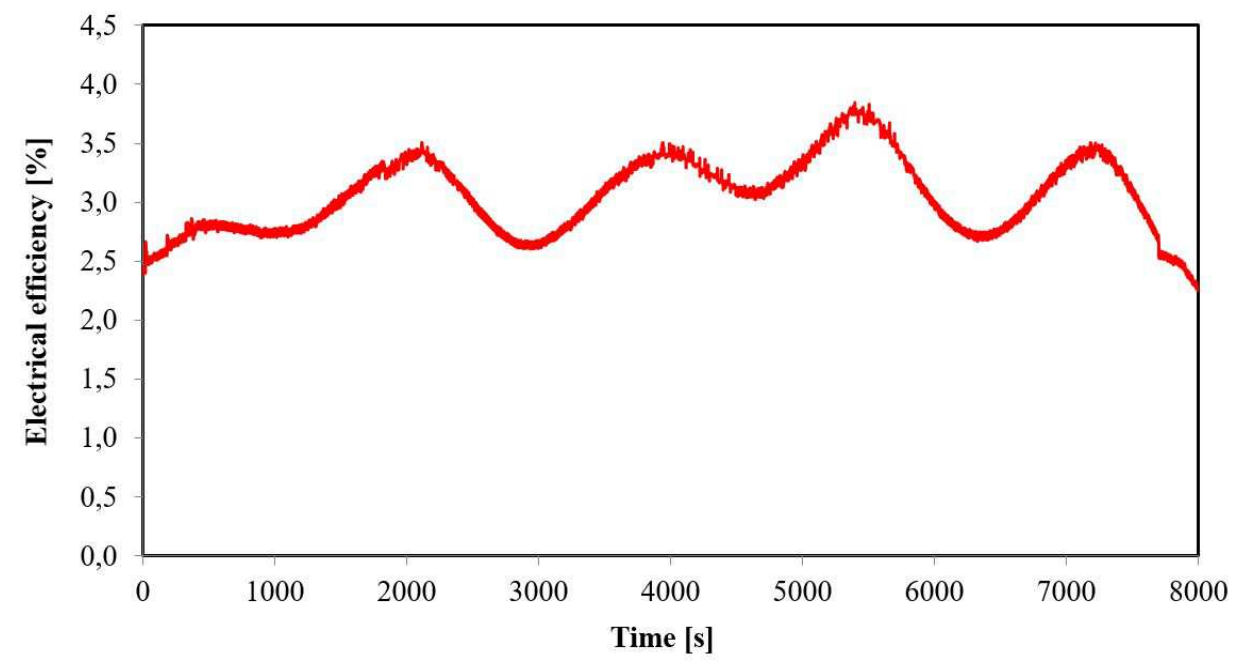

Fig. 6. Electrical efficiency of the ORC cogeneration boiler vs. time

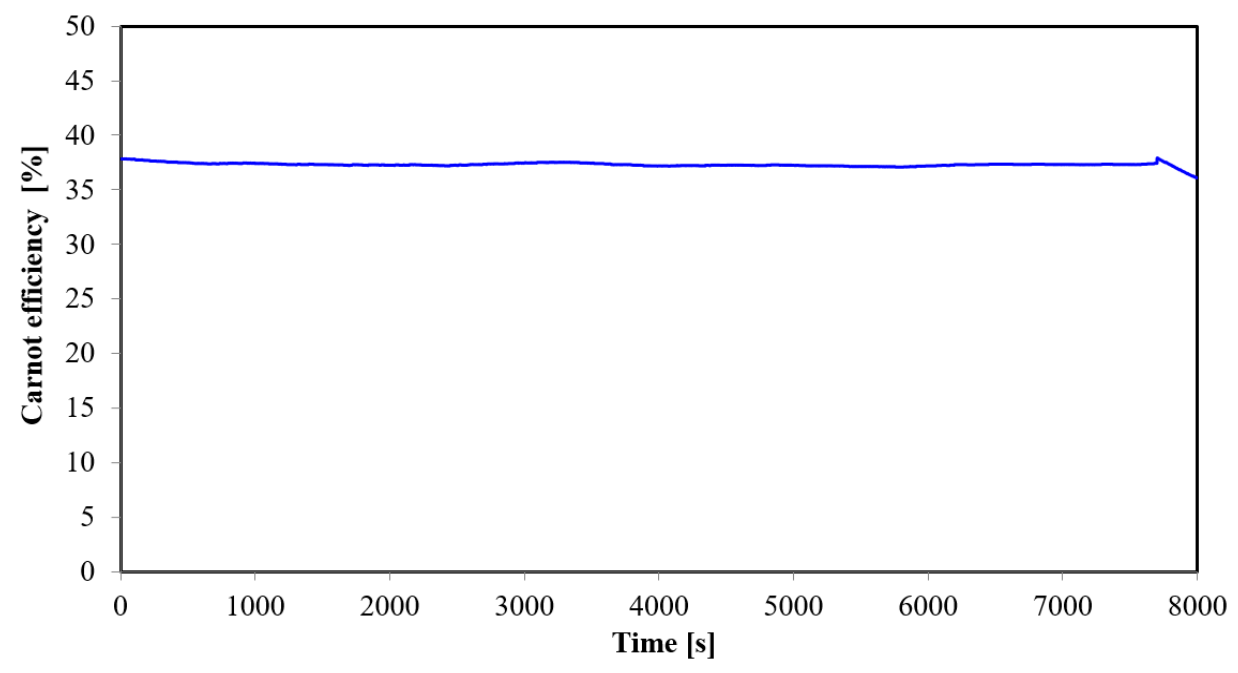

Fig. 7. Carnot efficiency of the ORC cogeneration system vs. time 
The result of the incorrect operation of the control system and fluctuations in the thermal power of the boiler was the low electrical efficiency of the ORC, which ranged from $2.5 \%$ to $3.9 \%$. The changes in the temperature of the HFE7100 medium resulted in changes in the temperature of the coolant (a solution of $40 \%$ ethylene glycol). As the matter of fact, it caused the Carnot efficiency of the cycle to be virtually constant during the research and its average value was approx. $37.2 \%$ (Fig. 7).

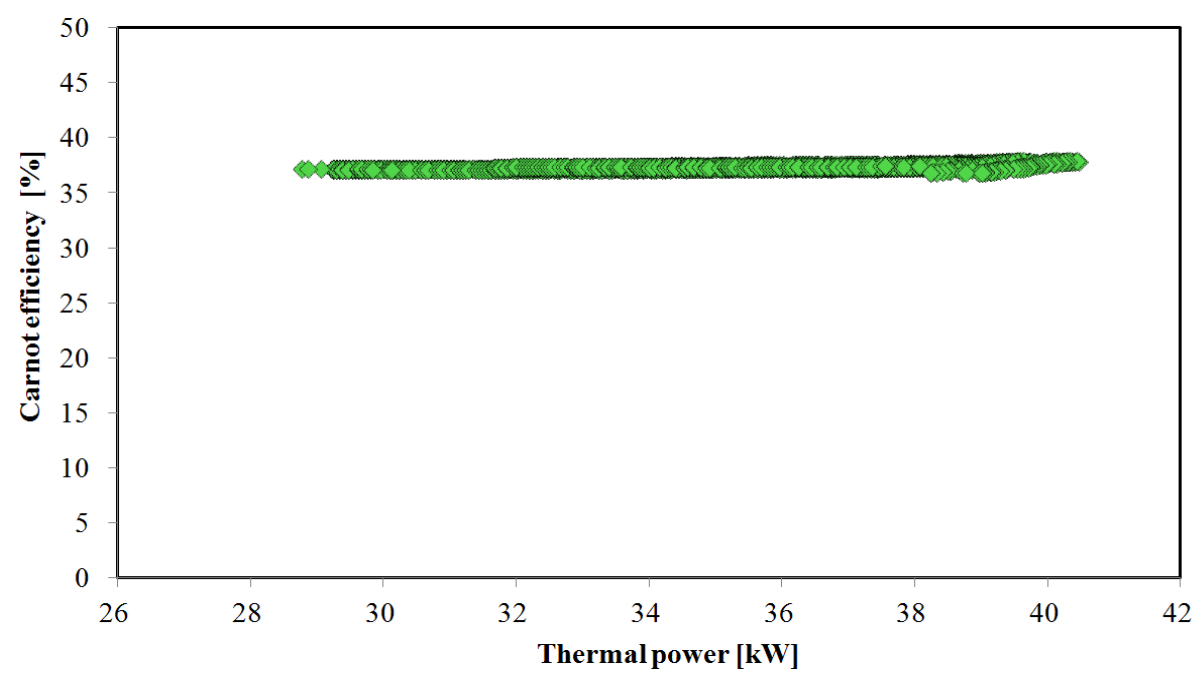

Fig. 8. Carnot efficiency of the ORC cogeneration system vs. thermal power of the boiler

According to the above statement, Carnot efficiency was constant and was not dependent on the thermal power of the biomass boiler, as shown in Fig. 8.

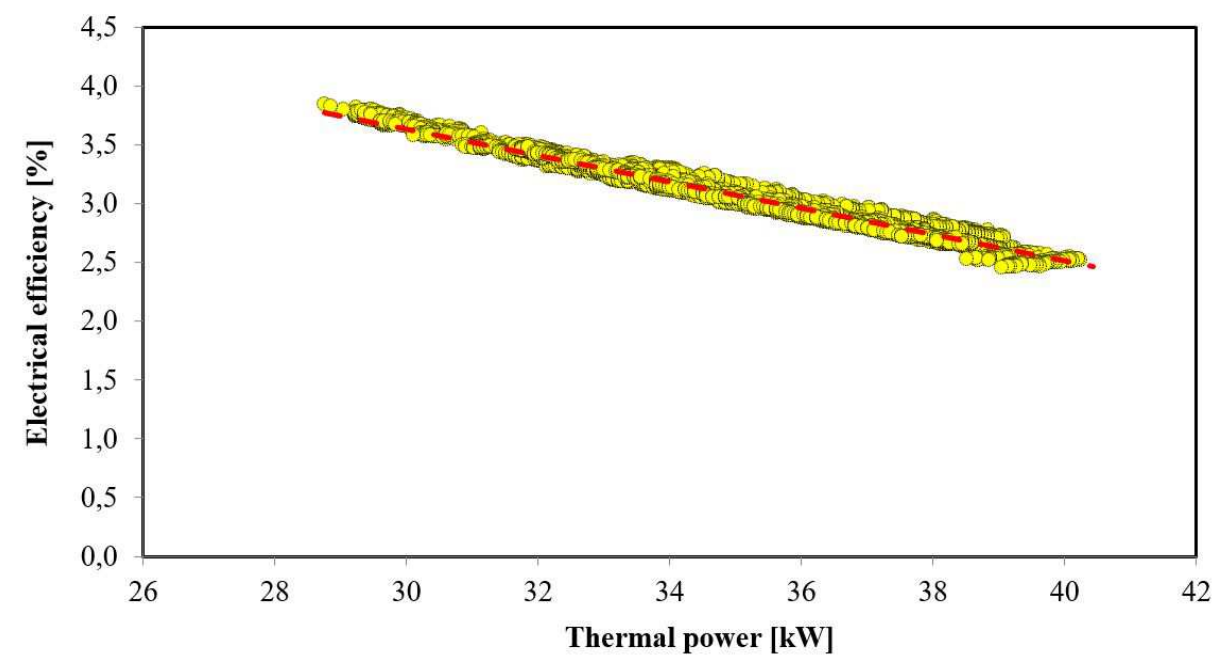

Fig. 9. Electrical efficiency of the ORC cogeneration system vs. thermal power of the boiler

Furthermore, it was found that the electrical efficiency of the ORC decreases as the thermal power of the boiler rises, which is depicted in Fig. 9.

It should be borne in mind that the microturbine worked practically at constant parameters (i.e. temperature, inlet pressure and flow rate of the working medium). What is more, the heat produced by the boiler was not effectively used by the microturbine but was directed to 
the cooling system, which affected the ORC system's electrical efficiency. On the other hand, the boiler operated at nominal parameters, striving to get the highest possible performance. It was found that biomass boilers operating in ORC systems should be selected according to nominal parameters of the expansion machine-in this case, the vapour microturbine. The oversized boiler caused significant heat waste that contributed to the low efficiency of the cogeneration cycle. Due to the very intense operation of vapour microturbines, boilers' thermal inertia should be as low as possible in order to ensure the optimal regime. Classic boilers with a heating jacket are characterised by high thermal inertia, which impairs the ability to control and regulate the system's operation. Besides, the control and regulation system for the boiler's components (i.e. feeder and air fan) should be properly calibrated depending on the type of working medium used (e.g. thermal oil). It should be borne in mind that the instability of parameters and any disturbances in the boiler's operation have a direct impact on the operation of the entire ORC cogeneration system.

\section{Conclusion}

After the tests of the $45 \mathrm{~kW}_{\mathrm{t}}$ biomass boiler coupled with during the ORC installation with an electric power of $2.5 \mathrm{~kW}_{\mathrm{e}}$, it was determined that the too high nominal power of the boiler caused a non-optimal operation of the entire cogeneration installation. It was also the reason for high heat losses and the low electrical efficiency of the ORC. The maximum electric efficiency of the ORC was about $3.9 \%$ and it decreased with an increase in the thermal power of the boiler. The maximum electric efficiency of the ORC was about 3.9\% and it decreased with an increase in the thermal power of the boiler. It was found that, regardless of the boiler's thermal power level, the Carnot efficiency was constant with a value of approx. $37.2 \%$. Moreover, it was stated that the control and regulation system for the subassemblies of the biomass boiler should be individually adapted to the working medium (heat carrier). An essential parameter affecting the operation of the entire cogeneration installation is the boiler's thermal inertia, which should be as small as possible (due to the intense operation of expansion machines). It would ensure an optimal operation in a wider power range.

\section{References}

1. Consumption of Fuels and Energy Carriers in 2013, Central Statistical Office (GUS), Warsaw 2014, in Polish.

2. Consumption of Fuels and Energy Carriers in 2014, Central Statistical Office (GUS), Warsaw 2015, in Polish.

3. Rahbar K., Mahmoud S., Al-Dadah R.K., Moazami N., Mirhadizadeh S.A., Review of organic Rankine cycle for small-scale applications, Energy Conversion and Management, 134, pp. 135-155, (2017)

4. Yaxuan X., Shuo A., Peng X., Yulong D., Chuan L., Qunli Z., Hongbing Ch., A novel expander-depending natural gas pressure regulation configuration: Performance analysis, Applied Energy, 220, pp. 21-35, (2018)

5. Zhu K., Li X., Campana P.E., Li H., Yan J., Techno-economic feasibility of integrating energy storage systems in refrigerated warehouses, Applied Energy, 216, pp. 348-357, (2018)

6. Lund H., Werner S., Wiltshire R., Svendsen S., Thorsen J.E., Hvelplund F., Mathiesen B.V., 4th Generation District Heating (4GDH): Integrating smart thermal grids into future sustainable energy systems, Energy, 111, pp. 923 - 932, (2016) 
7. Frigo S., Gabbrielli R., Puccini M., Seggiani M., Vitolo S., Small-Scale Wood-Fuelled CHP Plants: a Comparative Evaluation of the Available Technologies, Chemical Engineering Transactions, 37, pp. 847-852, (2014)

8. Liu H., Shao Y., Li J., A biomass-fired micro-scale CHP system with organic Rankine cycle (ORC) - Thermodynamic modelling studies, Biomass and Bioenergy, 35, pp. 3985-3994, (2011)

9. Onovwiona H.I., Ugursal V.I., Residential cogeneration systems: review of the current technology, Renewable and Sustainable Energy Reviews, 10, pp. 389-431, (2006)

10. Zywica G., Kaczmarczyk T.Z., Ihnatowicz E., A review of expanders for power generation in small-scale organic Rankine cycle systems: Performance and operational aspects, Proceedings of the Institution of Mechanical Engineers, Part A: Journal of Power and Energy, 230, 7, pp. 669-684), (2016)

11. Kaczmarczyk T.Z., Ihnatowicz E., Żywica G., Kiciński J., Experimental investigation of the ORC system in a cogenerative domestic power plant with a scroll expanders, Open Engineering, 5, pp. 411-420, (2015)

12. Rak J., Błasiak P., Kolasiński P., Influence of the Applied Working Fluid and the Arrangement of the Steering Edges on Multi-Vane Expander Performance in Micro ORC System, Energies, 11, 892, pp. 1-16, (2018)

13. Landelle A., Tauveron N., Haberschill P., Revellin R., Colasson S., Performance Evaluation and Comparison of Experimental Organic Rankine Cycle Prototypes from Published Data, Energy Procedia, 105, pp. 1706-1711, (2017)

14. Leśnikowska-Matusiak I., Wnuk A., The impact of transportation noise on the acoustic environment of man, Transport Samochodowy, 3, pp. 37-63, (2014)

15. Kaczmarczyk T.Z., Żywica G., Ihnatowicz E., Vibroacoustic diagnostics of a radial microturbine and a scroll expander operating in the organic Rankine cycle installation, Journal of Vibroengineering, 18, 6, pp. 4130-4147, (2016) 